International Journal of Pure and Applied Mathematics

Volume 115 No. 2 2017, 259-269

ISSN: 1311-8080 (printed version); ISSN: 1314-3395 (on-line version)

url: http://www.ijpam.eu

doi: 10.12732/ijpam.v115i2.5

ijpam.eu

\title{
A RELIABILITY MODEL FOR A SYSTEM WITH WRONG DIAGNOSIS ON FAILURE AND TWO TYPES OF REPAIRMAN
}

\author{
Charu Bala ${ }^{1}$, Anil Kumar Taneja $a^{2}$, \\ Hari Darshan Arora $^{3}$, Anita Taneja ${ }^{4}$ \\ ${ }^{1,3}$ Department of Mathematics \\ AIAS Noida, INDIA \\ ${ }^{2}$ Department of Mathematics \\ J.R.E. Group of Institutions \\ Gr. Noida, 201308, INDIA \\ ${ }^{4}$ Department of Mathematics \\ I.E.C. College of Engineering Technology \\ Gr. Noida, 201310, INDIA
}

\begin{abstract}
A reliability model is analyzed for a system wherein chances of wrong diagnosis are there on its failure. On failure, the system is undertaken for repair by an ordinary repairman with the possibility that the repair done by him may be found improper. As soon as the improper repair is revealed after putting it into operation, it goes under repair of an expert repairman. The analysis of the system is done by making use of regenerative point technique. Profit fetched by the system is evaluated with interesting results.
\end{abstract}

AMS Subject Classification: 60K15, 90B25, 60K10

Key Words: wrong diagnosis, regenerative point technique, measure of system effectiveness, profit analysis

\section{Introduction}

In order to meet increasing demands of society, industries are moving towards

Received: December 13, 2016

Revised: $\quad$ May 22, 2017

Published: July 14, 2017

(c) 2017 Academic Publications, Ltd. url: www.acadpubl.eu

$\S_{\text {Correspondence author }}$ 
automation of their industrial processes and systems. There is now huge change in technology and hence more complex systems are being introduced. Due to complexity of systems, the faults which occur therein are, sometimes, not properly diagnosed. A lot of work has been reported by various researchers including [1-6] in the literature of reliability but the aspect of wrong diagnosis has not been taken into account as far as the profitability of the systems is concerned. As the wrong diagnosis takes place in many situations, therefore it is inevitable to develop a reliability model for a system introducing this concept.

Thus, in the present paper, reliability and profit analysis has been done introducing the concept of improper diagnosis for a system with two types of repairman-ordinary as well as an expert repairman. On failure of the system, an inspection is carried out to detect as to whether the unit is repairable or irreparable and then it is repaired or replaced accordingly by the ordinary repairman. There is possibility that the ordinary repairman may do the wrong diagnosis which leads to improper repair/replacement which is revealed only when the system is kept under observation for some time after such repair/replacement. On observing the system for some time, system may be found in one of the following three conditions:

i) System is working as new as it was.

ii) It is not functioning properly (wrong diagnosis found).

iii) It fails during observation period.

If wrong diagnosis comes to the notice, the system is undertaken by the expert repairman for repair or replacement as the case may be; and if it fails during the observation period, the system is undertaken by the expert for inspection to detect as to whether it is repairable or not and hence repair or replacement is done accordingly. It is assumed that the expert does the inspection/repairs/replacement correctly.

Regenerative point technique is used for obtaining different measures of the system effectiveness. Profit incurred to the system is also analysed.

\section{Notation}

$f(t): \quad$ p.d.f. of failure time of the unit;

$p_{1}$ : $\quad$ probability that unit is found repairable on diagnosis by the ordinary repairman;

$q_{1}: \quad 1-p_{1}$;

$h(t), H(t): \quad$ p.d.f. and c.d.f. of inspection time of ordinary repairman; 
$g_{1}(t), G_{1}(t): \quad \quad$ p.d.f. and c.d.f. of repair time of ordinary repairman;

$g_{2}(t), G_{2}(t)$ : $\quad$ p.d.f. and c.d.f. of replacement time taken by ordinary repairman;

$\mathrm{i}(\mathrm{t}), \mathrm{I}(\mathrm{t}):$

$p_{2}$ :

p.d.f. and c.d..f. of time for which unit is under observation; probability that unit is found properly repaired by the ordinary repairman after the observation period.;

$q_{2}: \quad 1-p_{2}$;

$h_{e}(t), H_{e}(t)$ : $\quad$ p.d.f. and c.d.f. of inspection time taken by expert repairman;

$g_{e 1}(t), G_{e 1}(t): \quad$ p.d.f. and c.d.f. of repair time taken by the expert repairman;

$g_{e 2}(t), G_{e 2}(t): \quad$ p.d.f. and c.d.f. of replacement time taken by expert repairman.

Symbols for the states of the system:

op: operative unit;

uo : the unit is operative and under observation;

$F_{i}:$

$F_{r}:$ failed unit under inspection of ordinary repair man;

$f_{r p}$ : failed unit under repair of ordinary repair man;

$F_{i e}$ : failed unit under replacement of ordinary repair man;

$F_{r e}:$

$F_{\text {rpe }}$ : failed unit under inspection of expert repair man; failed unit under repair of expert repair man; failed unit under replacement by expert repair man.

\section{Transition Probabilities}

The diagram shown in Figure 1 represents transitions on the basis of various possibilities experienced by the system as per model description given in the introduction. All the states are regenerative states as future development from each state is independent of past and depends only on the present state. States 0 and 4 are up states, and the states 1, 2, 3, 5, 6 and 7 are failed states.

The transition probabilities are given by:

$$
\begin{aligned}
& q_{01}(t)=f(t), \quad q_{12}(t)=p_{1} h(t), \quad q_{13}(t)=q_{1} h(t), \\
& q_{24}(t)=g_{1}(t), \quad q_{34}(t)=g_{2}(t), \quad q_{40}(t)=p_{2 i}(t), \\
& q_{45}(t)=q_{2 i}(t), \quad q_{56}(t)=p_{1} h_{e}(t), \quad q_{57}(t)=q_{1} h_{e}(t), \\
& q_{60}(t)=g_{e} 1(t), \quad q_{70}(t)=g_{e} 2(t) \text {. }
\end{aligned}
$$




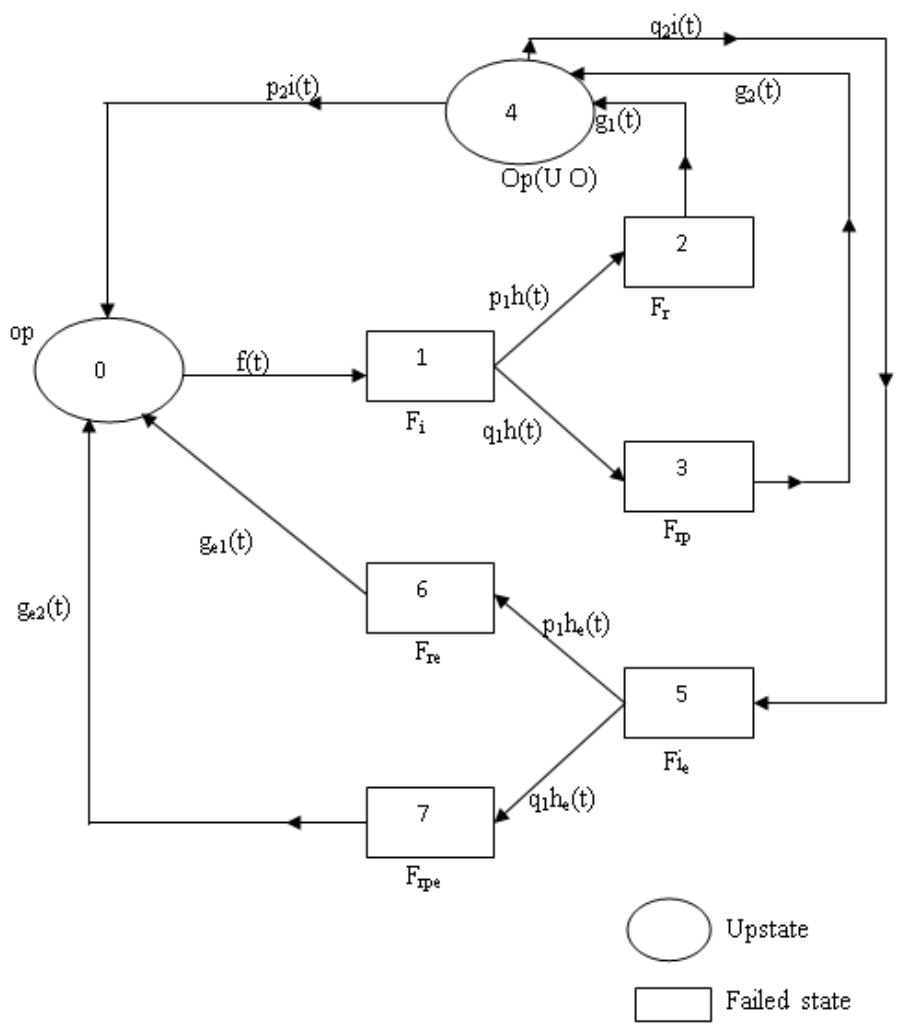

Figure 1: State transition diagram

The non zero elements $p_{i j}$ are obtained as follows

$$
p_{i j}=\lim _{s \rightarrow 0} q_{i j}^{*}(s)
$$

where $q_{i j}(s)$ is the Laplace transform of $q_{i j}(t)$.

From these transition probabilities, it can be verified that

$$
\begin{array}{lll}
p_{01}=1, & p_{12}+p_{13}=1, & p_{24}=1, \\
p_{341}=1, & p_{40}+p_{45}=1, & p_{56}+p_{57}=1, \\
p_{60}=1, & p_{70}=1 .
\end{array}
$$

The expected time of stay in state $i$ before getting transit to any other state 
is called the mean sojourn time in state $i$. Let it be denoted by $\mu_{i}$. Thus:

$$
\begin{aligned}
\mu_{0}=\int_{0}^{\infty} t f(t) d t & =-f^{*}(0), & \mu_{1} & =\int_{0}^{\infty} t h(t) d t=-h^{*}(0), \\
\mu_{2}=\int_{0}^{\infty} t g_{1}(t) d t & =-g_{1}^{*}(0), & \mu_{3} & =\int_{0}^{\infty} t g_{2}(t) d t=-g_{2}^{*}(0), \\
\mu_{4}=\int_{0}^{\infty} t i(t) d t & =-i^{*}(0), & \mu_{5} & =\int_{0}^{\infty} t h_{e}(t) d t=-h_{e}^{*}(0), \\
\mu_{6}=\int_{0}^{\infty} t g_{e 1}(t) d t & =-g_{e 1}^{*}(0), & \mu_{7} & =\int_{0}^{\infty} t g_{e 2}(t) d t=-g_{e 2}^{*}(0) .
\end{aligned}
$$

The unconditional mean time taken by the system to transit for any regenerative state $j$ when it is counted from epoch of entrance into state $i$ is mathematically stated as

$$
m_{i j}=\int_{0}^{\infty} t d Q_{i j}(t),
$$

So

$$
\begin{gathered}
m_{01}=\mu_{0}, \quad m_{12}+m_{13}=\mu_{1}, \quad m_{24}=\mu_{2}, \quad m_{34}=\mu_{3}, \\
m_{56}+m_{57}=\mu_{5}, \quad m_{40}+m_{45}=\mu_{4}, \quad m_{60}=\mu_{6}, \quad m_{70}=\mu_{7} .
\end{gathered}
$$

\section{Measures of System Effectiveness}

\subsection{Reliability and Mean Time to System Failure of the System}

Defining $\phi_{i}(t)$ as cumulative distribution function of the first passage time from regenerative state $\mathrm{i}$ to a failed state. We have

$$
\phi_{0}(t)=Q_{01}(t)
$$

The reliability $R(t)$ of the system at time $t$ is given as

$$
R(t)=\text { Inverse Laplace transform of } \frac{1-\varphi_{0}^{* *}(s)}{s}
$$


The mean time to system failure (MTSF) when the system starts from the state 0 is

$$
\begin{aligned}
\operatorname{MTSF} & =\int_{0}^{\infty} R(t) d t \\
& =\lim _{s \rightarrow 0} R^{*}(s) \\
& =\lim _{s \rightarrow 0} \frac{1-\phi_{0}^{* *}(s)}{s} \\
& =\mu_{0} .
\end{aligned}
$$

\subsection{Availability Analysis}

Availability of a system is expected fraction of the time in the long run that the system operate satisfactorily. We have the following recursive relation for $A_{i}(t)$ :

$$
\begin{aligned}
& \mathrm{A}_{0}(\mathrm{t})=\mathrm{M}_{0}(\mathrm{t})+\mathrm{q}_{01}(\mathrm{t})\left(\mathrm{c} \mathrm{A}_{1}(\mathrm{t}),\right. \\
& \mathrm{A}_{1}(\mathrm{t})=\mathrm{q}_{12}(\mathrm{t})\left(\mathrm{A}_{2}(\mathrm{t})+\mathrm{q}_{13}(\mathrm{t}) \odot \mathrm{A}_{3}(\mathrm{t})\right. \text {, } \\
& \mathrm{A}_{2}(\mathrm{t})=\mathrm{q}_{24}(\mathrm{t})\left(\mathrm{C} \mathrm{A}_{4}(\mathrm{t})\right. \text {, } \\
& \mathrm{A}_{3}(\mathrm{t})=\mathrm{q}_{34}(\mathrm{t}) \propto \mathrm{A}_{4}(\mathrm{t}) \text {, } \\
& \mathrm{A}_{4}(\mathrm{t})=\mathrm{M}_{4}(\mathrm{t})+\mathrm{q}_{40}(\mathrm{t})\left(\mathrm{C} \mathrm{A}_{0}(\mathrm{t})+\mathrm{q}_{45}(\mathrm{t})\left(\mathrm{C} \mathrm{A}_{5}(\mathrm{t})\right. \text {, }\right. \\
& \mathrm{A}_{5}(\mathrm{t})=\mathrm{q}_{56}(\mathrm{t}) \subset \mathrm{A}_{6}(\mathrm{t})+\mathrm{q} 57(\mathrm{t}) \subset \mathrm{A}_{7}(\mathrm{t}), \\
& \mathrm{A}_{6}(\mathrm{t})=\mathrm{q}_{60}(\mathrm{t})\left(\mathrm{C} \mathrm{A}_{0}(\mathrm{t})\right. \text {, } \\
& \mathrm{A}_{7}(\mathrm{t})=\mathrm{q}_{70}(\mathrm{t}) \propto \mathrm{A}_{0}(\mathrm{t}) \text {, }
\end{aligned}
$$

where $M_{i}(t)$ is the Probability that system up initially in regenerative state $\mathrm{i}$ is up at time 't' without passing through any other regenerative state and thus

$$
\begin{aligned}
M_{0}(t) & =\overline{F(t)}, \\
M_{4}(t) & =\bar{I}(t) .
\end{aligned}
$$

In steady-state, the availability of the system is given by

$$
A_{0}=\lim _{s \rightarrow 0}\left\{s A_{0}^{*}(s)\right\}=\frac{N_{1}}{D_{1}},
$$

where

$$
N_{1}=\mu_{0}+\mu_{4}
$$




$$
D_{1}=\mu_{0}+\mu_{1}+p_{12} \mu_{2}+p_{13} \mu_{3}+\mu_{4}+p_{45}\left(\mu_{5}+p_{56} \mu_{6}+p_{57} \mu_{7}\right) .
$$

Other measures of the system effectiveness can be obtained in the similar fashion and are given as follows:

1. Busy Period Analysis of the Ordinary Repairman (Inspection Time Only). The total fraction of time for which the system is under inspection by ordinary repairman is

$$
B_{0}^{i}=\lim _{s \rightarrow 0}\left\{s B_{0}^{i *}(s)\right\}=\frac{\mu_{1}}{D_{1}} .
$$

2. Busy Period Analysis of the Ordinary Repairman (Repair Time Only). In steady-state, the total fraction of the time for which the system is under repair of ordinary repairman is given by

$$
B_{0}^{r}=\frac{p_{12} \mu_{2}}{D_{1}}
$$

3. Busy Period Analysis of the Ordinary Repairman (Replacement Time Only). In steady-state, the total fraction of the time for which the system is under replacement of ordinary repairman is given by

$$
B_{0}^{r p}=\frac{p_{13} \mu_{3}}{D_{1}}
$$

4. Expected Observation Time. The total fraction of the time for which the system is under observation

$$
L_{0}=\frac{\mu_{4}}{D_{1}}
$$

5. Busy Period Analysis of the Expert Repairman (Inspection Time Only). The total fraction of time for which the system is under inspection of expert repairman is given by

$$
B_{0}^{i e}=\frac{p_{45} \mu_{5}}{D_{1}}
$$

6. Busy Period Analysis of the Expert Repairman (Repair Time Only). The total fraction of time for which the system is under repair of expert repairman is given by

$$
B_{0}^{r e}=\frac{\mathrm{p}_{45} \mathrm{p}_{56} \mu_{6}}{D_{1}}
$$


7. Busy Period Analysis of the Expert Repairman (Replacement Time Only). The total fraction of time for which the system is under replacement of expert repairman is given by

$$
B_{0}^{r e p e}=\frac{\mathrm{p}_{45} \mathrm{p}_{57} \mu_{7}}{D_{1}} .
$$

8. Expected Number of Visits by the Ordinary Repairman. The total number of visits of the ordinary repair person is given by

$$
V_{0}^{o}=\frac{1}{D_{1}}
$$

9. Expected Number of Visits by the Expert Repair Person. The total number of visits of the expert repair person is given by

$$
V_{0}^{e}=\frac{\mathrm{p}_{45}}{D_{1}}
$$

10. Expected Number of Replacements. The expected the number of replacements in the system is given by

$$
R_{0}=\frac{\mathrm{p}_{13}+\mathrm{p}_{45} \mathrm{p}_{57}}{D_{1}}
$$

\section{Profit Analysis}

On the basis of the above measures of the system effectiveness, the expected profit incurred to the system in steady-state is given by

$$
\begin{aligned}
P=C_{0} A_{0}-C_{1} B_{0}^{i}-C_{2} B_{0}^{r}-C_{3} B_{0}^{r p}-C_{4} L_{0}-C_{5} B_{0}^{i e}-C_{6} B_{0}^{r e} \\
-C_{7} B_{0}^{r e p e}-C_{8} V_{0}^{o}-C_{9} V_{0}^{e}-C_{10} R_{0},
\end{aligned}
$$

where

$C_{0}=$ Revenue per unit up time of the system

$C_{1}=$ Cost per unit time for which ordinary repair person is busy in inspection

$C_{2}=$ Cost per unit time for which ordinary repair person is busy in repair

$C_{3}=$ Cost per unit time for which ordinary repair person is busy in replacement

$C_{4}=$ Cost per unit time for which system is under observation.

$C_{5}=$ Cost per unit time for which expert repair person is busy in inspection. 
$C_{6}=$ Cost per unit time for which expert repair person is busy in repair

$C_{7}=$ Cost per unit time for which expert repair person is busy in replacement

$C_{8}=$ Cost per visit of the ordinary repair person

$C_{9}=$ Cost per visit of the expert repair person

$C_{10}=$ Cost per replacement

In order to have a profitable system, one can determine the least value of the revenue per unit up time of the system or the greatest value of each of the above costs from equation (65). While finding the value of one of these factors, the other parameters may be kept fixed.

\subsection{Least Value of Revenue per Unit Up Time}

The value of revenue per unit up time should be such that the profit given by equation (65) is positive, i.e.

$$
\begin{aligned}
C_{0} A_{0}-C_{1} B_{0}^{i}-C_{2} B_{0}^{r}- & C_{3} B_{0}^{r p}-C_{4} L_{0}-C_{5} B_{0}^{i e} \\
& -C_{6} B_{0}^{r e}-C_{7} B_{0}^{r e p e}-C_{8} V_{0}^{o}-C_{9} V_{0}^{e}-C_{10} R_{0}>0
\end{aligned}
$$

or

$$
\begin{aligned}
C_{0}>\frac{C_{1} B_{0}^{i}+C_{2} B_{0}^{r}+C_{3} B_{0}^{r p}+C_{4} L_{0}+C_{5} B_{0}^{i e}}{A_{0}} \\
+\frac{C_{6} B_{0}^{r e}+C_{7} B_{0}^{r e p e}+C_{8} V_{0}^{o}+C_{9} V_{0}^{e}+C_{10} R_{0}}{A_{0}} .
\end{aligned}
$$

Therefore, the price of the product manufactured by using the system should be kept in such a way so as to get the revenue not less than the value given on the right hand side of the inequality (66).

\subsection{Greatest Value of the Cost per Unit Time for Engaging Ordinary Repairman for Inspection}

The greatest value of the cost per unit time for which the ordinary repair person is busy for inspection for which the profit is positive is given by

$$
\begin{aligned}
C_{0} A_{0}-C_{1} B_{0}^{i}-C_{2} B_{0}^{r}- & C_{3} B_{0}^{r p}-C_{4} L_{0}-C_{5} B_{0}^{i e} \\
& -C_{6} B_{0}^{r e}-C_{7} B_{0}^{r e p e}-C_{8} V_{0}^{o}-C_{9} V_{0}^{e}-C_{10} R_{0}>0
\end{aligned}
$$

i.e. 


$$
\begin{aligned}
C_{1}<\frac{C_{0} A_{0}-C_{2} B_{0}^{r}-C_{3} B_{0}^{r p}-C_{4} L_{0}-C_{5} B_{0}^{i e}}{\mathrm{~B}_{0}^{\mathrm{i}}} \\
+\frac{-C_{6} B_{0}^{r e}-C_{7} B_{0}^{r e p e}-C_{8} V_{0}^{o}-C_{9} V_{0}^{e}-C_{10} R_{0}}{\mathrm{~B}_{0}{ }^{\mathrm{i}}} .
\end{aligned}
$$

So, one should not pay more than the amount as given on the right side of the inequality (67) to the ordinary repairman as otherwise the system will not be profitable.

Similarly, the greatest value for each of the other costs can be obtained in the similar manner so that system should be profitable.

\section{Conclusion}

A system with chances of wrong diagnosis are there on its failure has been analysed with regard to reliability and profitability. Finding various measures of the system effectiveness, expression for the profit has been obtained which will help in deciding as to how much the least value of the revenue per unit up time and how much the greatest value of each of the costs should be in order to have a profitable system.

\section{References}

[1] K.H. Wang, W.L. Dong, J.B. Ke, Comparison of reliability and the availability between four systems with warm standby components and standby switching failures, Applied Mathematics and Computation, 183 (2006), 1310-1322, doi: 10.1016/j.amc.2006.05.161.

[2] B. Parashar, G. Taneja, Reliability and profit evaluation of a PLC hot standby system based on a master-slave concept and two types of repair facilities, IEEE Transaction of Reliability, 56, No. 3 (2007), 534-539, doi: 10.1109/TR.2007.903151.

[3] A. Manocha, G. Taneja, R.K. Tuteja, Comparative profit analysis between two reliability model on ash water pump system with or without failed states, Int. J. Statist. Syst., 6 (2011), 9-16.

[4] Dalip Singh, G. Taneja, Reliability analysis of a power generating system through gas and steam turbines with scheduled inspection, Aryabhatta Journal of Mathematics and Informatics, 5, No. 2 (2013), 373-380.

[5] M.S. Kadyan, Reliability and profit analysis of a single unit system with preventive maintenance subject to maximum operation time, Maitenance and Reliability, 15, No. 2 (2013), 176-181.

[6] R. Malhotra, G. Taneja, Stochastic analysis of a two-unit cold standby system wherein both units may become operative depending upon the demand, J. Qual. Reliab Eng. (2014), doi: 10.1155/2014/896379. 
[7] N. Padmavathi, S.M. Rizwan, Anita Pal, G. Taneja, Pobablistic analysis of a desalination plant with major and minor failures and shut down during winter season, International Journal of Scientific and Statistical Computing, 5, No. 1 (2014), 15-23. 
